\title{
INGLÊS E INFORMÁTICA NA EDUCAÇÃO INFANTIL - O CÓDIGO ESCRITO É POSSÍVEL?
}

\author{
Elisabete Bohrer de Azevedo \\ Maria do Carmo Barbosa Trevisan
}

\section{INTRODUÇÃO}

A influência da exposição da escrita em língua inglesa a crianças no contexto do letramento informatizado foi uma questão de grande relevância para nosso grupo de trabalho, formado por professores da área de letramento, de Informática e de língua Inglesa, empenhados em realizar um trabalho integrado nos moldes da pesquisa-ação em uma instituição particular de ensino de Santa Maria (RS). Essa investigação exigiu, ao longo de todo um ano letivo, muita observação, reflexão, discussão e pesquisa bibliográfica.

Inicialmente, no desenvolvimento das aulas de língua inglesa em turmas em fase de letramento, não era dada ênfase à palavra escrita. As crianças escreviam seus nomes ao lado da palavra name na folha de atividades, o mês em inglês e os numerais referentes ao dia e ano ao lado da palavra date. Às vezes, as crianças pediam para escrever as palavras e expressões do contexto no qual no qual estavam realizando a atividade, no momento, e então estas palavras eram escritas no quadro.

No entanto, com o passar do ano letivo, já no início do segundo semestre, observamos um interesse emergente das crianças em relação à escrita das palavras em língua inglesa. Em vista disso, um questionamento impôs-se nesse momento para o grupo de docentes-reflexivos: as crianças poderiam encontrar dificuldades de aprendizagem ao serem expostas à escrita em língua inglesa estando em fase de aquisição da escrita e da leitura em língua materna?

Ao planejarmos as atividades para serem desenvolvidas no laboratório de informática, tínhamos a possibilidade de utilizar, através do computador, a pronúncia do inglês e as marcas visuais das palavras, isto é, a escrita. Entretanto, precisávamos de respaldo teórico e da especificação dos aspectos relevantes do contexto numa prática que sustentasse este procedimento.

A princípio, decidimos assinalar os aspectos mais importantes que caracterizavam o contexto no qual realizávamos a investigação: o inglês era ensinado como uma língua estrangeira às crianças de 5-6 anos de idade em uma escola da rede particular de ensino. Quanto ao perfil das crianças, a maioria tinha convivência com o inglês fora do ambiente escolar através da televisão, jogos e computador. Eram crianças observadoras, questionadoras e empenhadas na busca de conhecimento. Quanto ao trabalho docente, os professores estavam reunidos num grupo reflexivo-colaborativo e empenhados num esforço pela didática interdisciplinar (letramento / inglês / informática). 
Além de assinalar os aspectos mais importantes do contexto, procuramos estabelecer pontos relevantes do processo de aquisição da linguagem de modo geral, a fim de que pudéssemos assinalar também os pontos relevantes que servissem de base para apoiar um estudo mais especificamente voltado à aprendizagem de uma língua estrangeira. Para isso, avaliamos a bibliografia concernente ao assunto, utilizando as obras dos autores mais importantes, além de artigos, reportagens e textos em geral coletados em cursos, revistas, jornais e textos encontrados nas páginas da Internet.

\section{OS FUNDAMENTOS TEÓRICOS E A PRÁTICA EM QUESTÃO}

No que se refere especificamente ao ensino de uma língua estrangeira a crianças em classes de Educação Infantil, ou seja, em fase de letramento na língua materna, tivemos alguma dificuldade em encontrar material teórico disponível que pudesse dar subsídios à questão de haver ou não interferência na aprendizagem, o fato de introduzir-se, concomitantemente, a escrita de palavras em língua estrangeira. Porém, com a assessoria do orientador deste trabalho, decidimos consultar material sobre teorias da aquisição em situação de bilingüismo, na tentativa de encontrar questões relacionadas à situação que enfrentávamos, no que, felizmente, fomos bem-sucedidos.

Quando estávamos preparando atividades para serem utilizadas pelas crianças no laboratório de informática, decidimos, após reflexão e discussão sobre o contexto, o perfil de aluno e as leituras feitas sobre o assunto, elaborar atividades que utilizassem o código escrito com base no referido material coletado. Tínhamos, então, de um lado, um contexto favorável à aquisição multicognoscente e em conseqüência um perfil de aluno que evidenciava um cotidiano repleto de muitas informações; e, de outro, finalmente, uma bibliografia de apoio.

$\mathrm{Na}$ primeira atividade elaborada foram utilizados os números de 1 a 10 associados a personagens conhecidos de desenhos animados. Foram apresentados os numerais, seus nomes escritos em inglês e suas respectivas quantidades. Outras atividades, nestes moldes, foram elaboradas e desenvolvidas com os alunos. Outra atividade realizada posteriormente e que merece menção foi baseada em uma pequena história de um livro. As gravuras desta foram digitalizadas e um pequeno diálogo foi escrito como nas histórias em quadrinhos. Foram utilizados recursos de som e imagem. Os programas Power Point e Windows da Microsoft foram empregados para elaborar esta atividade.

De acordo com Cazden et al. (1990), o maior elemento do desenvolvimento infantil de crianças de 0 a 6 anos de idade é a linguagem. O desenvolvimento da linguagem, nesta fase, culmina no desenvolvimento de algumas habilidades metalingüísticas e retóricas, que auxiliarão o letramento, no início da escolaridade. Tendo como base esse argumento, percebemos que poderíamos relacioná-lo com as estratégias utilizadas para a elaboração da atividade. Por exemplo, a contextualização através das gravuras e história; a ludicidade presente nas gravuras, no contexto e no diálogo; e as marcas visuais reforçando o diálogo oral com algumas palavras em inglês já conhecidas pelas crianças, auxiliavam, na nossa hipótese explicativa, o desenvolvimento das inferências que as crianças 
fazem acerca da linguagem.

Além disso, a prevalência do multilingüísmo no mundo acrescenta uma particular urgência em observar a qualidade dos contextos nos quais a linguagem é desenvolvida. É estimado que $60 \%$ das crianças do mundo crescerão em situações que exigirão o uso de mais de uma língua. O bilingüísmo não constitui por si só um risco para o desenvolvimento das crianças - ao contrário, elas devem ter somente vantagens cognitivas em relação às crianças monolíngües, além da vantagem óbvia de conhecer duas línguas. (op.cit., 1990). Com isso, compreendemos que, ao utilizarmos o contexto de aprendizagem da língua materna para expor à criança uma outra língua, de modo contextualizado e lúdico a fim de tornar o processo mais natural possível, estaremos contribuindo para que ela desenvolva a percepção de que pode usar outros códigos para comunicar-se.

Paiva (1998) declara que devemos estimular nas crianças o seu potencial para transitar em diferentes culturas (isto é, realizar a alternância de códigos culturais), sem que venham a perder ou ter afetada a sua própria identidade, seus referenciais culturais. Nas atividades que elaboramos, procuramos propiciar o reconhecimento das duas línguas e/ ou as diferentes culturas através do contexto (história) e da função comunicativa ( palavras e expressões).

Segundo Ferreiro (2001), o significado do ler e escrever mudam com o tempo. Ela afirma que o ler e o escrever têm a ver com as marcas visuais, mas o que se espera do leitor é determinado numa certa época ou cultura. Em relação a esta afirmação, é possível relacioná-la com a estratégia utilizada: empregar palavras em inglês que estão no cotidiano das crianças, mais conhecidas em conseqüência da sua utilização tanto na mídia quanto nas tecnologias mais recentes. Por exemplo: bye- bye; play. A autora também declara que os jovens têm facilidade para se adaptar a mudanças. Eles aprendem a usar a Internet em situação doméstica, sem instrução escolar; logo, lidam com as novas tecnologias de uma forma muito familiar. Isto nos levou a incluir os recursos da informática que viabilizam som e imagem na tela do computador.

De acordo com Cazden et al. (apud Wells,1990), a única e mais importante influência na aprendizagem da leitura das crianças no Ensino Fundamental está relacionada com suas experiências diretas com o código escrito na fase préescolar. Os autores acrescentam que existem muitas maneiras específicas nas quais as experiências de letramento na educação infantil preparam as crianças para o ensino fundamental. Por exemplo: acompanhando a leitura dos adultos em voz alta; fazendo perguntas sobre palavras em livros ou sinais no ambiente social; tentando escrever por conta própria, mesmo inventando signos; valorizando a função da leitura (entendendo que a escrita é útil em nosso meio). Em suma, essas atividades contribuem para reduzir os riscos de fracasso no ensino fundamental.

Ao desenvolver as atividades de exposição integrada com as crianças, o grupo de trabalho não constatou quaisquer problemas, tanto no que diz respeito ao ensino da língua materna quanto no que toca ao ensino do inglês como língua estrangeira, com a utilização do código escrito em língua inglesa. Essas 
observações vão ao encontro dos autores a que vimos fazendo referência. No que diz respeito à antes mencionada história em gravuras digitalizadas, as crianças souberam lidar naturalmente com as letras escritas na tela do computador e entusiasmaram-se com o contexto da narrativa, inclusive demonstrando compreendê-la. As estratégias utilizadas forneceram pistas para que as crianças compreendessem o seu enredo: a introdução do contexto da história pela professora de inglês; a disposição das gravuras em seqüência lógica; os questionamentos feitos pelo docente durante o desenvolvimento da atividade e os comentários feitos pelos alunos.

\section{CONCLUSÃO}

Diante dos resultados da pesquisa realizada, com base nos dados coletados relativos ao contexto analisado, ao perfil dos alunos e as referências bibliográficas minuciosamente avaliadas, podemos concluir que, em um contexto que favoreça uma aquisição multicognoscente pela criança, isto é, um ambiente rico de informações, onde ela seja estimulada a participar como sujeito do seu próprio conhecimento, não haverá receio de conduzi-la cada vez mais aos desafios da linguagem, inclusive o do trabalho escolar bilíngüe. Atualmente, as crianças, em especial os alunos da rede particular de ensino, têm contato com o código escrito ou com os sinais no ambiente social, o que favorece significativamente o desenvolvimento das habilidades lingüísticas. Além disso, quanto mais a criança se familiariza com os vários aspectos da linguagem durante a educação infantil, favorecendo, com isso, seu desenvolvimento lingüístico, mais estará favorecido o desenvolvimento cognitivo, pois, durante esta fase, a linguagem e a cognição estão diretamente relacionadas.

$\mathrm{Na}$ nossa investigação, ficou claro que apresentar, no contexto anteriormente relatado, palavras, expressões e mesmo pequenas frases em língua inglesa, tal como se procede em língua materna, não acresce dificuldades de aprendizagens às crianças. Pelo contrário, contribui-se para uma aprendizagem mais efetiva, visto que há, atualmente, uma exigência maior da escola e do ambiente social (pressões do contexto) sobre as questões atinentes aos atos de ler e escrever. Portanto, considerando-se que as crianças estejam realmente envolvidas desde o início da educação infantil com os vários aspectos da linguagem, isto é, tenham a oportunidade de lidar com letras e com os sons que estas letras representam, como escrever palavras significativas como seus próprios nomes, ter contato com livros e histórias, mesmo sem iniciar a aprendizagem formal da leitura, terão com este tipo de background um bom começo para qualquer tipo de letramento. (Cazden et al, 1998)

\section{BIBLIOGRAFIA:}

CAZDEN, Courtney B. et al. Language Planning in Preschool Education. Massachusetts: Cambridge, 1990.

FERREIRO, Emília. O ato de ler evolui. In: Revista Nova Escola. Junho/Julho 2001.

PAIVA, Maria da Graça. Os desafios do ensinar a ler e escrever em língua estrangeira. In: NEVES lara Conceição(org.) Ler e escrever: compromisso de 
todas as áreas. Porto Alegre: Ed. UFRGS, 1998.

TOMAS, Lucia \& GIL, Vicky. Super Me 1. Oxford: Oxford University Press, 2000. 